\title{
PENGARUH SUHU DAN LAMA PENYANGRAIAN (ROASTING) TERHADAP SIFAT FISIK DAN KIMIA PADA SEDUHAN KOPI ARABIKA (Coffea Arabica L.) DARI KABUPATEN GAYO, PROVINSI ACEH
}

\author{
Meiko Taqwa Pamungkas ${ }^{1}$, Masrukan, Kuntjahjawati
}

\begin{abstract}
Coffee quality can be improved by one of the most important post-harvest handling processes, namely the roasting process. The purpose of this study was to determine the effect of temperature and roasting time on the quality of Gayo Arabica coffee. This research uses Arabica coffee beans that come from the district which are really festive which are ready to be roasted. This research used factorial completely randomized design (CRD) with the treatment of roasting temperature variations of $190^{\circ} \mathrm{C}, 200^{\circ} \mathrm{C}$ and $210^{\circ} \mathrm{C}$ with a roasting time of 5 minutes, 10 minutes and 15 minutes. Data analysis was performed using analysis of variance (Anova) with further test of Duncan's new multiple range test (DNMRT). Analysis parameters include yield, moisture content, ash content, fat content, total acid content, caffeine and organoleptic tests were carried out on 30 panelists. In this study, the best results were obtained at a temperature treatment of $200^{\circ} \mathrm{C}$ with a roasting time of 10 minutes which had a score of 3.53 which means like it and a little like it, the yield was $78.5 \%$, the water content was $1.34 \%$, the ash content was $4.55(\%)$. db), fat content $14.48(\% \mathrm{db})$, caffeine 0.87 (\% $\mathrm{db})$ and total acid $1.34(\% \mathrm{db})$.
\end{abstract}

Keywords: arabica coffee, roasting, flavours

\begin{abstract}
ABSTRAK
Mutu kopi bisa ditingkatkan dengan salah satu proses penanganan pasca panen yang sangat penting yaitu proses penyangraian. Tujuan penelitian ini untuk mengetahui pengaruh suhu dan lama penyangraian terhadap mutu kopi arabika gayo. Penelitian ini menggunakan biji kopi arabika yang berasal dari kabupaten bener meriah yang sudah siap untuk disangrai. Penelitian ini menggunakan rancangan acak lengkap (RAL) faktorial dengan perlakuan variasi suhu penyangraian $190^{\circ} \mathrm{C}, 200^{\circ} \mathrm{C}$ dan $210^{\circ} \mathrm{C}$ dengan lama penyangraian 5 menit, 10 menit dan 15 menit. Analisa data dilakukan dengan analysis of variance (Anova) dengan uji lanjut beda nyata Duncan's new multiple range test (DNMRT). Parameter analisis meliputi rendemen, kadar air, kadar abu, kadar lemak, kadar asam total, kafein dan dilakukan uji organoleptik terhadap 30 orang panelis. Pada penelitian ini hasil terbaik didapatkan pada perlakuan suhu $200^{\circ} \mathrm{C}$ dengan lama penyangraian 10 menit yang memiliki skor 3,53 yang berarti suka dan sedikit suka, rendemen 78,5\%, kadar air $1,34 \%$, kadar abu 4,55(\%db), kadar lemak 14,48(\%db), kafein 0,87(\%db) dan total asam 1,34(\%db).
\end{abstract}

Kata kunci: kopi arabika, penyangraian, flavor

\section{PENDAHULUAN}

Minuman adalah segala bentuk cairan yang pada umumnya masuk tubuh kita dengan melalui mulut obat-obatan. Minuman yang biasa dikonsumsi sehari-hari oleh masyarakat adalah teh, sirup, jus dan kopi. Minuman kopi dalam pemahaman masyarakat umum selama ini selalu dikaitkan dengan kafein yang sering dianggap punya efek negatif terhadap kesehatan. Minuman kopi juga diduga sebagai penyebab nyeri lambung karena seduhan kopi memang bersifat asam. Salah satu senyawa yang memberi rasa asam di dalam kopi adalah senyawa asam klorogenat dan asam klorogenat di dalam biji kopi juga bersifat sebagai senyawa antioksidan jenis polifenol yang sangat bermanfaat bagi kesehatan tubuh dan dapat berfungsi untuk mencegah gejala kanker usus, diabetes dan beberapa penyakit degeneratif lainnya. Seduhan kopi Arabika mempunyai nilai pH sekitar 5, sedangkan nilai $\mathrm{pH}$ seduhan kopi

\footnotetext{
${ }^{1}$ Program Studi Teknologi Pangan Fakultas Sains dan Teknologi Universitas Widya Mataram Yogyakarta $\triangle$ miekotq@gmail.com
} 
robusta berkisar 5,50. Biji kopi yang ditanam di dataran tinggi mengandung senyawa asam lebih banyak daripada biji kopi yang berasal dari dataran rendah (Mulato, 2002).

Sejak abad ke-19 kopi dari Nusantara telah Minuman adalah segala bentuk cairan yang pada umumnya masuk tubuh kita dengan melalui mulut obat-obatan. Minuman yang biasa dikonsumsi sehari-hari oleh masyarakat adalah teh, sirup, jus dan kopi. Minuman kopi dalam pemahaman masyarakat umum selama ini selalu dikaitkan dengan kafein yang sering dianggap punya efek negatif terhadap kesehatan. Minuman kopi juga diduga sebagai penyebab nyeri lambung karena seduhan kopi memang bersifat asam. Salah satu senyawa yang memberi rasa asam di dalam kopi adalah asam senyawa klorogenat dan asam klorogenat di dalam biji kopi juga bersifat sebagai senyawa antioksidan jenis polifenol yang sangat bermanfaat bagi kesehatan tubuh dan dapat berfungsi untuk mencegah gejala kanker usus, diabetes dan beberapa penyakit degeneratif lainnya. Seduhan kopi Arabika mempunyai nilai $\mathrm{pH}$ sekitar 5, sedangkan nilai $\mathrm{pH}$ seduhan kopi robusta berkisar 5,50. Biji kopi yang ditanam di dataran tinggi mengandung senyawa asam lebih banyak daripada biji kopi yang berasal dari dataran rendah (Mulato, 2002).

Sejak abad ke-19 kopi dari Nusantara telah digunakan sebagai komoditas unggulan daerah masing-masing seperti Aceh, Mandailing, Toraja serta Sidikalang telah menguasai pasar dunia. Badan Pusat Statistik daera Aceh Gayo mencatat dari tahun 2015 - 2017 produksi kopi Gayo meningkat dari 47,44 ton menjadi 68,49 ton, namun masih banyak orang yang mengeluhkan tentang citarasa kopi Arabika Gayo yang cenderung asam yang diduga karena kopi arabika mengandung lebih banyak senyawa asam dibandingkan dengan kopi robusta.

Kopi juga mengandung alkaloid xantin (purin), yakni kafein. Kafein merupakan SSP (Stimulan Saraf Pusat) dan merupakan suatu produk yang sangat populer di antara para pelajar untuk mengatasi keletihan dan kantuk. Senyawa ini juga merupakan diuretik dan digunakan dalam kombinasi analgesik. Didalam seduhan kopi, kafein adalah salah satu senyawa yang memberikan rasa pahit pada seduhannya (Heinrich, 2010).
Seduhan kopi Arabika Gayo merupakan salah satu minuman yang dikenal dan disukai oleh masyarakat di Sumatera. Biasa diminum pagi dan atau malam hari. Memiliki aroma dari campuran aroma yang diantaranya karamel, vanila, fruity dan smoky sehingga membentuk aroma kopi yang khas. Kopi tersebut memiliki karakter rasa, aroma dan body yang kuat, sedikit asam seperti buah, sedikit spicy dan manis-pahit sehingga membentuk flavor khas kopi Gayo. Flavor kopi tersebut akan keluar setelah biji kopi di sangrai. Tidak hanya di Sumatera, kopi Gayo juga digemari oleh masyarakat dunia. Oleh karena itu, nilai ekonomi kopi Gayo cukup tinggi dan selama ini biji kopi Gayo banyak yang di ekspor ke luar negeri. Kopi Arabika Gayo adalah kopi yang berasal dari Kabupaten Bener Meriah yang terletak didataran tinggi Gayo, kabupaten ini merupakan kabupaten hasil pemekaran wilayah Kabupaten Aceh Tengah. Kebanyakan masyarakat di daerah tersebut memiliki kebiasaan mengkonsumsi kopi sebagai minuman yang cukup digemari, hal ini dapat diketahui berdasarkan fakta di lapangan bahwa hampir diseluruh pelosok desa maupun kota terdapat warung kopi dari yang sederhana sampai yang mewah dan selalu dipadati dan dicari oleh konsumen. Selain itu bubuk kopi juga menjadi kebutuhan konsumsi di tingkat rumah tangga.

Proses penyangraian kopi beras adalah proses pembentukan rasa, warna dan aroma pada seduhan kopi melalui proses pirolisis dari karbohidrat pada biji kopi (hemiselulosa, selulosa, lignin) yang akan terdekomposisi pada suhu sekitar 200-260 ${ }^{\circ} \mathrm{C}$ menjadi senyawa-senyawa yang lebih sederhana. Dalam (Kuntjahjawati dan Darmadji, 2004) menyebutkan bahwa selulosa, hemiselulosa, lignin pada proses pirolisis akan terdekomposisi menjadi senyawa sederhana golongan furan, karbonil, fenol dan gula reduksi. Beberapa senyawa yang terbentuk bersifat larut dalam air. Pada seduhan kopi akan membentuk rasa, warna dan aromanya. Selain itu, biji kopi mentah yang belum disangrai mengandung kafein dan asam klorogenat. Menurut Mulato (2002), Kandungan asam klorogenat akan mengalami penurunan cukup signifikan selama penyangraian pada tingkat penyangraian gelap, konsentrasi asam klorogenat menurun secara drastis yang semula 120 menjadi tinggal $12 \mathrm{mg} / \mathrm{g}$ sampel. Sivetz (1973), mengatakan 
struktur kimia kafein stabil terhadap suhu sangrai dan trigonelin hanya kehilangan $10 \%$ selama penyangraian.

Menurut EFSA, batas aman konsumsi kafein adalah $319 \mathrm{mg}$ per hari bagi orang yang sehat, sedangkan bagi orang yang memiliki riwayat penyakit seperti darah tinggi dianjurkan hanya mengkonsumsi kafein 150-200 mg per hari. Disamping itu untuk asam klorogenat dianjurkan mengkonsumsinya dibawah $1000 \mathrm{mg}$ perhari. Tingkat roasting yang banyak digunakan untuk kebutuhan kafe atau rumahan biasanya adalah medium roast $\left(210-220^{\circ} \mathrm{C}\right)$ dengan rata-rata konsumsi kopi di Indonesia adalah 2 cangkir dan paling banyak bisa sampai 4 cangkir perhari atau setara dengan $400 \mathrm{mg}$ kafein dan $280 \mathrm{mg}$ asam klorogenat perhari pada biji kopi medium roast (Mangiwa, 2013). Masyarakat konsumen kopi arabika biasanya mengeluhkan adanya rasa asam dan rasa yang sangat pahit pada seduhan kopinya.

Oleh sebab itu, untuk memperoleh kopi yang tidak terlalu asam karena mengandung asam klorogenat dan tidak menaikkan kadar kafein menjadi terlalu tinggi agar tidak menjadi terlalu pahit dan dapat diminum oleh banyak orang, maka diperlukan proses penyangraian yang tepat agar kandungan asam klorogenat pada kopi tidak memberikan rasa asam yang tinggi serta kafein tidak melonjak tinggi dan memberikan rasa yang sangat pahit.

Berdasarkan pertimbangan diatas, maka perlu diadakan penelitian mengenai proses penyangraian biji kopi untuk mengetahui cara penyangraian, rasa, suhu, waktu dan metode untuk menghasilkan kopi yang disukai oleh konsumen.

\section{BAHAN DAN METODE}

\section{Bahan}

Bahan yang digunakan pada penelitian ini antara lain adalah aquades, gas, kertas label dan greenbean Arabika Gayo Aceh (KA 12\%) didapat dari Kedai Kopi Aman Kuba Jl. Bantul Suryodiningratan, Kec. Mantirejon, Kota Yogyakarta.

Alat-alat yang akan digunakan pada penelitian ini adalah cawan, desikator, gelas cup, gelas ukur, grinder (GETRA IC-06B 1500 watt $2500 \mathrm{rpm} 300$ gr), Kamera digital (12MP V1.0 Android 10), Mesin penyangrai kopi (Homemade roaster 1000 gr), oven, panci, penyaring 80 mesh, sendok, stopwatch, thermometer,dan timbangan.

\section{Proses penelitian}

Biji kopi hijau disiapkan sebanyak 200 gram setiap perlakuan, kemudian biji kopi disangrai pada suhu $\left(190^{\circ} \mathrm{C}, 200^{\circ} \mathrm{C}, 210^{\circ} \mathrm{C}\right)$ dengan waktu sangrai $(5,10,15$ menit) dan diulang 3 kali. Setelah dihasilkan kopi sangrai dilakukan penimbangan berat kopi untuk mengukur rendemen kopi. Selanjutnya dilakukan resting selama 7 hari. Setelah melalui proses resting kemudian dilakukan penggilingan biji kopi setelah itu dilakukan penyaringan dengan ayakan 80 mesh sehingga menghasilkan kopi bubuk. Kopi bubuk kemudian disiapkan sebanyak 0,5 gram untuk dilakukan analisis kadar air dan kadar abu. 1 gram untuk analisa lemak serta perbandingan seduhan (1:15) kopi dan air untuk uji organoleptik.

\section{Analisa data}

Pengolahan data dilakukan menggunakan Rancangan Acak Lengkap (RAL), faktorial dengan dua faktor yang diuji yaitu suhu penyangraian (A) yang terdiri atas 3 taraf yaitu (A1), (A2) dan (A3) dan lama penyangraian (B) terdiri dari 3 taraf yaitu (B1), (B2) dan (B3). Data yang diperoleh dianalisa dengan menggunakan analisa ragam ANOVA dan apabila ada perbedaan antar perlakuan dilanjutkan dengan metode DMRT.

\section{HASIL DAN PEMBAHASAN \\ Rendemen Kopi Arabika Gayo}

Hasil Analisis sidik ragam rendemen kopi Arabika Gayo menunjukkan bahwa rendemen kopi Arabika Gayo dipengaruhi oleh variasi suhu penyangraian secara nyata yang dimana semakin tinggi suhu penyangraian maka rendemen semakin turun. Hal ini diduga karena terjadinya penguapan air dan semakin banyak terbentuknya senyawa volatil yang menguap sehingga rendemen menjadi turun. Hasil uji lanjut DMRT pengaruh suhu penyangraian dapat dilihat pada Tabel 1 bahwa rendemen yang diperoleh pada suhu penyangraian $190^{\circ} \mathrm{C}$ berbeda nyata dengan suhu $200^{\circ} \mathrm{C}$. Rendemen yang diperoleh pada suhu penyangraian $200^{\circ} \mathrm{C}$ berbeda nyata dengan suhu $210^{\circ} \mathrm{C}$. Penyangraian pada suhu $190^{\circ} \mathrm{C}$ menghasilkan rendemen tertinggi yaitu $84,5 \%$ dan rendemen 
terendah terdapat pada perlakuan suhu $210^{\circ} \mathrm{C}$ yaitu $67 \%$.

Tabel 1. Hasil analisis suhu penyangraian terhadap rendemen kopi Arabika Gayo

\begin{tabular}{ccc}
\hline $\begin{array}{c}\text { Perlakuan } \\
\text { suhu }\left({ }^{\circ} \mathbf{C}\right)\end{array}$ & $\begin{array}{c}\text { Rerata } \\
\text { rendemen }(\%)\end{array}$ & Notasi \\
\hline 190 & 84,5 & $\mathrm{c}$ \\
200 & 78 & $\mathrm{~b}$ \\
210 & 67 & $\mathrm{a}$ \\
\hline
\end{tabular}

Keterangan :

-Huruf yang berbeda menandakan adanya interaksi pada perlakuan (Berbeda Nyata).

Hasil analisis sidik ragam rendemen kopi Arabika Gayo menunjukkan bahwa rendemen kopi Arabika Gayo tidak dipengaruhi oleh variasi lama penyangraian secara nyata. Hasil uji lanjut DMRT pengaruh lama penyangraian dapat dilihat pada Tabel 2 . Rendemen yang diperoleh pada lama penyangraian 5 menit tidak berbeda nyata dengan rendemen yang diperoleh pada lama penyangraian 10 menit. Rendemen yang diperoleh pada lama penyangraian 10 menit tidak berbeda nyata dengan rendemen yang diperoleh pada lama penyangraian 15 menit.

Tabel 2. Hasil analisis waktu penyangraian terhadap rendemen kopi Arabika Gayo

\begin{tabular}{ccc}
\hline $\begin{array}{c}\text { Perlakuan } \\
\text { waktu (menit) }\end{array}$ & $\begin{array}{c}\text { Rerata } \\
\text { rendemen }(\%)\end{array}$ & Notasi \\
\hline 5 & 78,5 & $\mathrm{a}$ \\
10 & 77 & $\mathrm{a}$ \\
15 & 74 & $\mathrm{a}$ \\
\hline
\end{tabular}

Keterangan :

-Huruf yang berbeda menandakan adanya interaksi pada perlakuan (Berbeda Nyata).

Hasil penelitian ini menunjukkan bahwa rendemen kopi yang diperoleh setelah proses penyangraian seperti terlihat pada Tabel 3 . Persentase rendemen hasil penyangraian tertinggi diperoleh pada suhu $190^{\circ} \mathrm{C}$ dan lama penyangraian 5 menit dengan total rendemen yaitu $85,5 \%$. Sedangkan persentase rendemen yang paling rendah pada suhu $210^{\circ} \mathrm{C}$ dan lama penyangraian 15 menit dengan total rendemen yaitu $63,5 \%$. Semakin tinggi suhu dan lama penyangraian maka semakin rendah rendemen yang dihasilkan. Hal ini sesuai dengan pernyataan Sivetz dan Foote (1973) bahwa rendemen juga dipengaruhi oleh susut berat biji kopi selama penyangraian, semakin lama waktu penyangraian rendemen akan menjadi semakin kecil. Hal ini diduga karena terjadinya proses pirolisis yang menyebabkan menguapnya air dan senyawa-senyawa volatil yang terbentuk sehingga semakin tinggi suhu dan lama penyangraian maka rendemen akan semakin berkurang.

Tabel 3. Hasil analisa suhu dan waktu penyangraian terhadap rendemen kopi Arabika Gayo

\begin{tabular}{ccccc}
\hline $\begin{array}{c}\text { Suhu } \\
\left({ }^{\circ} \mathbf{C}\right)\end{array}$ & \multicolumn{3}{c}{$\begin{array}{c}\text { Lama Penyangraian } \\
\text { (menit) }\end{array}$} & $\begin{array}{c}\text { Rerata } \\
\text { rendemen } \\
(\%)\end{array}$ \\
\cline { 2 - 4 } & $\mathbf{5}$ & $\mathbf{1 0}$ & $\mathbf{1 5}$ & $(\%)$ \\
\hline $\mathbf{1 9 0}$ & $85,5(\mathrm{~g})$ & $84,5(\mathrm{fg})$ & $83,5(\mathrm{fg})$ & $84,5(\mathrm{c})$ \\
$\mathbf{2 0 0}$ & $80,5(\mathrm{ef})$ & $78,5(\mathrm{de})$ & $75(\mathrm{~d})$ & $78(\mathrm{~b})$ \\
$\mathbf{2 1 0}$ & $69,5(\mathrm{bc})$ & $68(\mathrm{ab})$ & $63,5(\mathrm{a})$ & $67(\mathrm{a})$ \\
$\begin{array}{c}\text { Rerata } \\
\text { rendemen }\end{array}$ & & & & \\
$(\%)$ & $78,5(\mathrm{a})$ & $77(\mathrm{a})$ & $74(\mathrm{a})$ & \\
\hline $\boldsymbol{\%})$ & & &
\end{tabular}

Keterangan :

-Huruf yang berbeda menandakan adanya interaksi pada perlakuan (Berbeda Nyata).

-Huruf yang sama menandakan tidak adanya interaksi pada perlakuan (Tidak Berbeda Nyata).

\section{Kadar Air Kopi Arabika Gayo}

Hasil uji lanjut DMRT 5\% pengaruh suhu penyangraian terhadap kadar air kopi Arabika Gayo dapat dilihat pada Tabel 4 bahwa penyangraian suhu $190^{\circ} \mathrm{C}$ berbeda nyata dengan suhu $200^{\circ} \mathrm{C}$ dan kadar air yang diperoleh pada suhu penyangraian $200^{\circ} \mathrm{C}$ tidak berbeda nyata dengan suhu penyangraian $200^{\circ} \mathrm{C}$. Kadar air kopi Arabika Gayo terendah diperoleh pada suhu penyangraian $210^{\circ} \mathrm{C}$. Hal ini diduga karena semakin tinggi suhu maka akan semakin banyak melepaskan air. Pada suhu $190^{\circ} \mathrm{C}$ akan melepaskan air bebas dan sebagian air terikat, pada suhu $200^{\circ} \mathrm{C}$ akan melepaskan air terikat dan sebagian air terikat kuat dan pada suhu $210^{\circ}$ akan melepaskan air terikat kuat dan sebagian air terikat ionik. Pengaruh variasi lama penyangraian terhadap kadar air kopi Arabika Gayo dapat dilihat pada Tabel 5.

Tabel 4. Hasil analisa suhu penyangraian terhadap kadar air kopi Arabika Gayo 


\begin{tabular}{ccc}
\hline $\begin{array}{c}\text { Perlakuan } \\
\text { suhu }\left({ }^{\circ} \mathbf{C}\right)\end{array}$ & $\begin{array}{c}\text { Rerata kadar } \\
\text { air }(\boldsymbol{\%})\end{array}$ & Notasi \\
\hline 190 & 2,57 & $\mathrm{~b}$ \\
200 & 1,38 & $\mathrm{a}$ \\
210 & 0,75 & $\mathrm{a}$ \\
\hline
\end{tabular}

Keterangan :

-Huruf yang berbeda menandakan adanya interaksi pada perlakuan (Berbeda Nyata).

Hasil analisis sidik ragam kadar air kopi Arabika Gayo menunjukkan bahwa uji lanjut DMRT pengaruh lama penyangraian dapat dilihat pada Tabel 5 dimana kadar air yang diperoleh pada lama penyangraian 5 menit berbeda nyata dengan lama penyangraian 15 menit. Kadar air yang diperoleh pada lama penyangraian 5 menit tidak berbeda nyata dengan lama penyangraian 10 menit. Hal ini diduga karena semakin lama waktu penyangraian maka suhu juga akan perlahan ikut naik sehingga air yang dilepaskan juga akan semakin banyak.

Tabel 5. Hasil analisa waktu penyangraian terhadap kadar air kopi Arabika Gayo

\begin{tabular}{ccc}
\hline $\begin{array}{c}\text { Perlakuan } \\
\text { waktu (menit) }\end{array}$ & $\begin{array}{c}\text { Rerata kadar } \\
\text { air }(\%)\end{array}$ & Notasi \\
\hline 5 & 2,02 & $\mathrm{a}$ \\
10 & 1,51 & $\mathrm{ab}$ \\
15 & 1,18 & $\mathrm{~b}$ \\
\hline
\end{tabular}

Keterangan :

-Huruf yang berbeda menandakan adanya interaksi pada perlakuan (Berbeda Nyata).

Selama proses penyangraian berlangsung, terjadinya proses perpindahan panas dan massa air dari silinder pemanas ke biji kopi arabika, biji kopi menunjukkan penurunan kadar air sesuai dengan (Estiasih, 2009) bahwa semakin lama waktu penyangraian maka semakin cepat pindah panas ke bahan pangan dan semakin cepat pula penguapan air dari bahan pangan.

Pada Tabel 6 menunjukkan penelitian kopi bubuk arabika memenuhi syarat SNI-01-35422004 yaitu kadar air bubuk kopi maksimal 7\%, hal ini menunjukkan semakin lama waktu sangrai dari kadar air awal 12\% turun menjadi 0,76-3,52\%. Dapat dilihat pada perubahan kadar air kopi gayo akibat variasi suhu dan lama penyangraian. Kadar air kopi tertinggi diperoleh pada suhu penyangraian $190^{\circ} \mathrm{C}$ dengan lama penyangraian 5 menit yaitu $3,52 \%$, sedangkan kadar air yang paling rendah diperoleh pada suhu penyangraian $210^{\circ} \mathrm{C}$ lama penyangraian 5 menit yaitu $0,74 \%$. Terlihat bahwa kadar air kopi akan semakin berkurang dengan bertambahnya waktu penyangraian dan semakin tingginya suhu penyangraian. Hal ini diduga karena terjadinya reaksi Maillard, karamelisasi, pirolisis dan pengarangan sehingga pada penyangraian kopi pada suhu $190^{\circ} \mathrm{C}$ akan melepaskan air bebas dan sebagian air terikat, pada suhu $200^{\circ} \mathrm{C}$ akan melepaskan air terikat dan sebagian air terikat kuat dan pada suhu $210^{\circ} \mathrm{C}$ akan melepaskan air terikat kuat dan sebagian air terikat ionik. Air yang tersisa pada suhu $210^{\circ} \mathrm{C}$ diduga adalah air terikat ionik yang belum menguap.

Tabel 6. Hasil analisa suhu dan waktu penyangraian terhadap kadar air kopi Arabika Gayo

\begin{tabular}{crrrr}
\hline Suhu $\left({ }^{\circ} \mathbf{C}\right)$ & \multicolumn{3}{c}{ Lama Penyangraian (menit) } & $\begin{array}{c}\text { Rerata } \\
\text { kadar }\end{array}$ \\
\cline { 2 - 4 } & 5 & 10 & 15 & air $(\%)$ \\
\hline $\mathbf{1 9 0}$ & $3,52(\mathrm{~d})$ & $2,41(\mathrm{c})$ & $1,78(\mathrm{bc})$ & $2,57(\mathrm{~b})$ \\
$\mathbf{2 0 0}$ & $1,81(\mathrm{bc})$ & $1,34(\mathrm{ab})$ & $0,99(\mathrm{a})$ & $1,38(\mathrm{a})$ \\
$\mathbf{2 1 0}$ & $0,74(\mathrm{a})$ & $0,78(\mathrm{a})$ & $0,75(\mathrm{a})$ & $0,75(\mathrm{a})$ \\
$\mathbf{R e r a t a}$ & & & & \\
kadar air & & & & \\
$(\%)$ & $2,02(\mathrm{a})$ & $1,51(\mathrm{ab})$ & $1,18(\mathrm{~b})$ \\
\hline Ket $)$
\end{tabular}

Keterangan :

-Huruf yang berbeda menandakan adanya interaksi pada perlakuan (Berbeda Nyata).

-Huruf yang sama menandakan tidak adanya interaksi pada perlakuan (Tidak Berbeda Nyata).

\section{Kadar Abu Kopi Arabika Gayo}

Kadar abu merupakan jumlah mineral yang terdapat pada biji kopi antara lain kalium, kalsium, magnesium dan mineral non logam antara lain fosfor dan sulfur. Tinggi rendahnya kadar abu pada biji kopi tergantung pada kandungan mineral pada bahan (Yuhandini, 2008).

Hasil uji lanjut DMRT 5\% pengaruh suhu penyangraian terhadap kadar abu dapat dilihat pada Tabel 7 bahwa penyangraian suhu $190^{\circ} \mathrm{C}$ tidak berbeda nyata dengan suhu $200^{\circ} \mathrm{C}$ dan kadar abu yang diperoleh pada suhu penyangraian $200^{\circ} \mathrm{C}$ tidak berbeda nyata dengan suhu penyangraian $210^{\circ} \mathrm{C}$ yang dimana rata-rata kadar abu yang diperoleh adalah sekitar 4,56\% - 4,54\%. Hal ini diduga karena kadar abu stabil teradap pemanasan. Pengaruh variasi lama penyangraian terhadap kadar abu kopi Arabika Gayo dapat dilihat pada Tabel 8.

Tabel 7. Hasil analisa suhu penyangraian teradap kadar abu kopi Arabika Gayo

\begin{tabular}{ccc}
\hline $\begin{array}{c}\text { Perlakuan suhu } \\
\left({ }^{\circ} \mathbf{C}\right)\end{array}$ & $\begin{array}{c}\text { Rerata kadar } \\
\text { abu }(\% d b)\end{array}$ & Notasi \\
\hline
\end{tabular}




\begin{tabular}{lll}
\hline 190 & 4,56 & $\mathrm{a}$ \\
200 & 4,55 & $\mathrm{a}$ \\
210 & 4,54 & $\mathrm{a}$ \\
\hline
\end{tabular}

Keterangan :

-Huruf yang sama menandakan tidak adanya interaksi pada perlakuan (Tidak Berbeda Nyata).

Hasil analisis sidik ragam kadar abu kopi Arabika Gayo menunjukkan bahwa uji lanjut DMRT pengaruh lama penyangraian dapat dilihat pada Tabel 8 dimana kadar abu yang diperoleh pada lama penyangraian 5 menit tidak berbeda nyata dengan lama penyangraian 10 menit dan 15 menit. Hal ini diduga karena kadar abu stabil teradap waktu pemanasan.

Tabel 8. Hasil analisa waktu penyangraian teradap kadar abu kopi Arabika Gayo

\begin{tabular}{ccc}
\hline $\begin{array}{c}\text { Perlakuan } \\
\text { waktu (menit) }\end{array}$ & $\begin{array}{c}\text { Rerata kadar } \\
\text { abu }(\% d \boldsymbol{d})\end{array}$ & Notasi \\
\hline 5 & 4,56 & $\mathrm{a}$ \\
10 & 4,55 & $\mathrm{a}$ \\
15 & 4,54 & $\mathrm{a}$ \\
\hline
\end{tabular}

Keterangan :

-Huruf yang sama menandakan tidak adanya interaksi pada perlakuan (Tidak Berbeda Nyata).

Hasil analisis ragam pada menunjukkan bahwa perbedaan suhu dan lama waktu penyangraian tidak berbeda nyata terhadap kadar abu bubuk kopi Arabika Gayo. Kadar abu merupakan residu anorganik dari proses pembakaran atau hasil oksidasi komponen organik bahan pangan. Kadar abu juga merupakan jumlah mineral yang terdapat pada bahan, adapun mineralmineral yang terkandung dalam kopi antara lain potasium, kalsium, magnesium dan mineral nonlogam antara lain fosfor dan sulfur (Clarke, 1987).

Penelitian ini menunjukkan tidak adanya interaksi suhu dan lama waktu penyangraian terhadap kadar abu kopi bubuk Arabika Gayo. Pada Tabel 9 secara statisrik nilai kadar abu pada kopi Arabika Gayo mengalami penurunan tetapi tidak memberikan pengaruh yang nyata. Menurut Harris (1989), menjelaskan bahwa mineral memiliki sifat yang tidak muda rusak akibat pengolahan, namun pengolaahn dapat menyebabkan susut mineral maksimal 3\% pada beberapa sumber mak anan, sehingga kadar abu dapat berkurang lebih dari $0,04 \%$.

Kandungan kadar abu pada penelitian ini masih diambang normal yaitu masih di kisaran 4,56
- 4,54\%, karena dalam SNI - 01 - 3542 - 2004 batas maksimal kadar abu kopi arabika sebesar 5\%. Tabel 9. Hasil analisa suhu dan lama penyangraian terhadap kadar abu kopi Arabika Gayo

\begin{tabular}{|c|c|c|c|c|}
\hline \multirow[t]{2}{*}{ Suhu $\left({ }^{\circ} \mathbf{C}\right)$} & \multicolumn{3}{|c|}{$\begin{array}{c}\text { Lama Penyangraian } \\
\text { (menit) }\end{array}$} & \multirow{2}{*}{$\begin{array}{c}\text { Rerata } \\
\text { kadar abu } \\
(\% d b)\end{array}$} \\
\hline & 5 & 10 & 15 & \\
\hline 190 & $4,56(a)$ & 4,56 (a) & 4,56 (a) & 4,56 (a) \\
\hline 200 & $4,56(a)$ & 4,55 (a) & 4,55 (a) & 4,55 (a) \\
\hline 210 & 4,55 (a) & 4,54 (a) & 4,54 (a) & 4,54 (a) \\
\hline $\begin{array}{c}\text { Rerata } \\
\text { kadar abu } \\
(\% d b)\end{array}$ & 4,56 (a) & 4,55 (a) & 4,54 (a) & \\
\hline
\end{tabular}

Keterangan :

-Huruf yang sama menandakan tidak adanya interaksi pada perlakuan (Tidak Berbeda Nyata).

\section{Lemak dan Minyak}

Lemak pada kopi terdapat di lapisan lilin pelindung biji dan pada minyak kopi. Lemak pada kopi berpengaruh dalam memberikan cita rasa pada seduhan kopi, yaitu meningkatkan body (rasa kental) dan milky (rasa lemak) (Buffo dan CardelliFreire, 2004). Kadar lemak dan minyak kopi Arabika Gayo terhadap variasi suhu penyangraian dapat dilihat pada tabel berikut.

Tabel 10. Hasil analisa suhu penyangraian terhadap kadar lemak kopi Arabika Gayo

\begin{tabular}{ccc}
\hline $\begin{array}{c}\text { Perlakuan } \\
\text { Suhu }\left({ }^{\circ} \mathbf{C}\right)\end{array}$ & $\begin{array}{c}\text { Rerata kadar } \\
\text { lemak }(\boldsymbol{\%} \boldsymbol{d} \boldsymbol{b})\end{array}$ & Notasi \\
\hline 190 & 14,49 & $\mathrm{a}$ \\
200 & 14,49 & $\mathrm{a}$ \\
210 & 14,49 & $\mathrm{a}$ \\
\hline
\end{tabular}

Keterangan :

-Huruf yang sama menandakan tidak adanya interaksi pada perlakuan (Tidak Berbeda Nyata).

Hasil analisis sidik ragam kadar lemak kopi Arabika Gayo menunjukkan bahwa uji lanjut DMRT pengaruh suhu penyangraian dapat dilihat pada tabel di atas dimana kadar lemak yang diperoleh pada suhu penyangraian $190^{\circ} \mathrm{C}$ tidak berbeda nyata dengan suhu penyangraian $200^{\circ} \mathrm{C}$ dan perlakuan suhu $210^{\circ} \mathrm{C}$. Hal ini diduga karena kadar lemak minyak stabil terhadap pemanasan. Pengaruh variasi lama penyangraian terhadap kadar lemak kopi Arabika Gayo dapat dilihat pada tabel berikut.

Tabel 11. Hasil analisa waktu penyangraian terhadap kadar lemak kopi Arabika Gayo 


\begin{tabular}{ccc}
\hline $\begin{array}{c}\text { Perlakuan } \\
\text { waktu (menit) }\end{array}$ & $\begin{array}{c}\text { Rerata kadar } \\
\text { lemak }(\boldsymbol{\%} \boldsymbol{d} \boldsymbol{b})\end{array}$ & Notasi \\
\hline 5 & 14,49 & $\mathrm{a}$ \\
10 & 14,49 & $\mathrm{a}$ \\
15 & 14,49 & $\mathrm{a}$ \\
\hline
\end{tabular}

Keterangan :

-Huruf yang sama menandakan tidak adanya interaksi pada perlakuan (Tidak Berbeda Nyata).

Hasil analisis sidik ragam kadar lemak kopi bubuk Arabika Gayo menunjukkan bahwa pengaruh lama penyangraian teradap kadar lemak kopi Arabika Gayo dapat dilihat pada tabel di atas dimana kadar lemak yang diperoleh pada lama penyangraian 5 menit tidak berbeda nyata dengan lama penyangraian 10 menit dan lama penyangraian 10 menit. Hal ini diduga karena kadar lemak minyak tidak terpengarruh terhadap lama pemanasan.

Tabel 12. Hasil analisa suhu dan lama penyangraian terhadap kadar lemak kopi Arabika Gayo

\begin{tabular}{|c|c|c|c|c|}
\hline \multirow{2}{*}{$\begin{array}{c}\text { Suhu } \\
\left({ }^{\circ} \mathbf{C}\right)\end{array}$} & \multicolumn{3}{|c|}{ Lama Penyangraian (menit) } & \multirow{2}{*}{$\begin{array}{l}\text { Rerata } \\
\text { kadar } \\
\text { lemak } \\
(\% d b)\end{array}$} \\
\hline & 5 & 10 & 15 & \\
\hline 190 & 14,49 (a) & 14,49 (a) & 4,49 (a) & 14,49 (a) \\
\hline 200 & 14,49 (a) & 14,48 (a) & 4,48 (a) & 14,49 (a) \\
\hline 210 & $14,48(a)$ & $14,48(a)$ & $\lfloor 4,48$ (a) & 14,49 (a) \\
\hline $\begin{array}{c}\text { Rerata } \\
\text { kadar } \\
\text { lemak } \\
(\% d b)\end{array}$ & 14,49 (a) & 14,49 (a) & 4,49 (a) & \\
\hline
\end{tabular}

Keterangan :

-Huruf yang sama menandakan tidak adanya interaksi pada perlakuan (Tidak Berbeda Nyata).

Berdasarkan tabel di atas dapat diketahui bahwa persentase kadar lemak kopi Arabika Gayo akan semakin menurun tetapi tidak signifikan seiring dengan menaiknya suhu dan lama penyangraian. Hal ini diduga karena kadar lemak minyak stabil teradap pemanasan dan akan sedikit menguap, minyak yang menguap diduga senyawa pembentuk aroma. Hasil analisis menunjukkan bahwa perbedaan suhu dan lama waktu penyangraian tidak berbeda nyata terhadap kadar lemak bubuk kopi Arabika Gayo.

\section{Kadar Kafein Kopi Arabika Gayo}

Hasil analisis ragam menunjukkan bahwa perbedaan suhu dan lama waktu penyangraian tidak berpengaruh nyata terhadap kafein bubuk kopi arabika, hal ini sesuai dengan yang dikatakan
(Sivetz, 1979) bahwa kafein stabil terhadap pemanasan. Rerata tertinggi kandungan kafein kopi bubuk arabika terdapat pada perlakuan suhu $210^{\circ} \mathrm{C}$ dengan waktu penyangraian 5 menit sebesar $0,89 \%$ dan terendah terdapat pada perlakuan suhu $190^{\circ} \mathrm{C}$ dengan lama penyangraian 5 menit sebesar $0,76 \%$.

Hasil penelitian pada Tabel 13 menunjukkan kenaikkan persentase kandungan kafein pada kopi bubuk Arabika Gayo, hal ini sesuai dengan Sutrisno (2006) kenaikkan kafein dikarenakan lama waktu penyangraian mempengaruhi proses terurainya zat cair dan zat asam sehingga jumlah kandungan zat non cair seperti kafein, lemak dan mineral persentasenya meningkat. Kandungan kafein kopi bubuk Arabika Gayo sudah memenuhi standar SNI-01-3542-2004 dengan maksimum $2 \%$ kandungan kafein.

Tabel 13. Hasil analisa suhu dan lama penyangraian terhadap kafein kopi Arabika Gayo

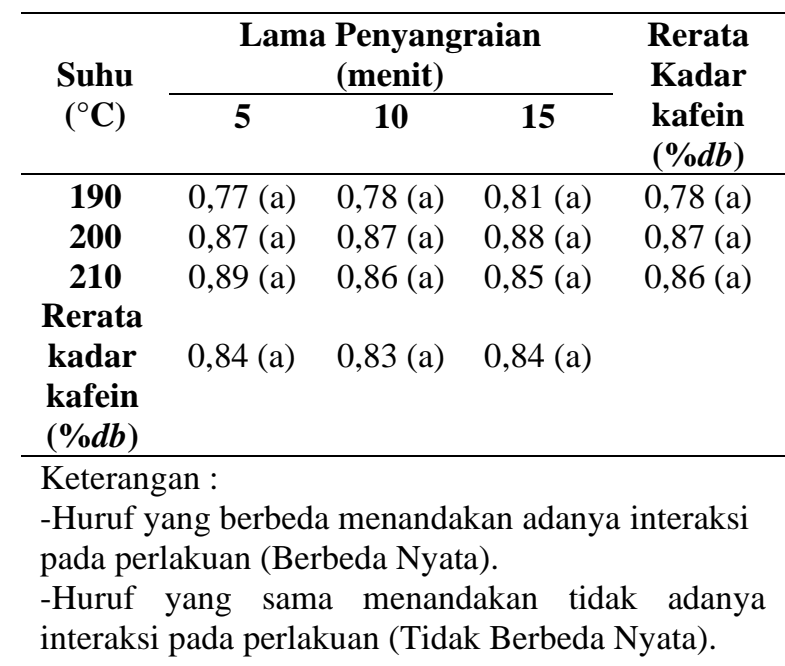

\section{Total Asam Tertitrasi}

Nilai asam tertitrasi adalah persentase asam dalam bahan yang ditentukan secara titrasi dengan basa standar (Herawati dan Wibawa, 2009). Total asam tertitrasi (TAT) dinyatakan dalam persen asam laktat. Nilai total asam tertitrasi dari kopi Arabika Gayo yang di sangrai dengan variasi suhu yang berbeda dapat dilihat pada tabel berikut.

Tabel 14. Hasil analisa suhu penyangraian terhadap total asam kopi Arabika Gayo

\begin{tabular}{ccc}
\hline $\begin{array}{c}\text { Perlakuan suhu } \\
\left({ }^{\circ} \mathbf{C}\right)\end{array}$ & $\begin{array}{c}\text { Rerata kadar } \\
\text { total asam } \\
(\% \text { db })\end{array}$ & Notasi \\
\hline 190 & 2,52 & $\mathrm{c}$ \\
200 & 1,42 & $\mathrm{~b}$ \\
\hline
\end{tabular}


210

0,74

a

Keterangan :

-Huruf yang berbeda menandakan adanya interaksi pada perlakuan (Berbeda Nyata)

Hasil uji lanjut DMRT 5\% pengaruh suhu penyangraian terhadap total asam tertitrasi pada kopi Arabika Gayo dapat dilihat pada tabel di atas bahwa penyangraian suhu $190^{\circ} \mathrm{C}$ berbeda nyata dengan suhu $200^{\circ} \mathrm{C}$ dan kadar total asam yang diperoleh pada suhu penyangraian $200^{\circ} \mathrm{C}$ juga berbeda nyata dengan suhu penyangraian $210^{\circ} \mathrm{C}$. Hal ini diduga karena semakin tinggi suhu maka senyawa-senyawa asam akan menguap.Kadar total asam kopi Arabika Gayo terendah diperoleh pada suhu penyangraian $210^{\circ} \mathrm{C}$ dan yang tertinggi diperoleh pada suhu $190^{\circ} \mathrm{C}$. Pengaruh variasi lama penyangraian terhadap kadar asam total kopi Arabika Gayo dapat dilihat pada tabel berikut.

Tabel 15. Hasil analisa waktu penyangraian terhadap total asam kopi Arabika Gayo

\begin{tabular}{ccc}
\hline $\begin{array}{c}\text { Perlakuan } \\
\text { waktu (menit) }\end{array}$ & $\begin{array}{c}\text { Rerata kadar } \\
\text { total asam } \\
(\boldsymbol{\%} \boldsymbol{d} \boldsymbol{b})\end{array}$ & Notasi \\
\hline 5 & 1,78 & $\mathrm{a}$ \\
10 & 1,63 & $\mathrm{~b}$ \\
15 & 1,27 & $\mathrm{c}$ \\
\hline
\end{tabular}

Keterangan :

-Huruf yang berbeda menandakan adanya interaksi pada perlakuan (Berbeda Nyata).

Hasil analisis sidik ragam total asam kopi Arabika Gayo menunjukkan bahwa uji lanjut DMRT pengaruh lama penyangraian dapat dilihat pada tabel di atas dimana total asam yang diperoleh pada lama penyangraian 5 menit tidak berbeda nyata dengan lama penyangraian 10 menit dan lama penyangraian 10 menit tidak berbeda nyata dengan lama penyangraian 15 menit. Hal ini diduga karena lama waktu penyangraian tidak terlalu berpengaruh nyata dengan suhu yang sama.

Tabel 16. Hasil analisa suhu dan waktu penyangraian terhadap total asam kopi Arabika Gayo

\begin{tabular}{ccccc}
\hline & \multicolumn{2}{c}{$\begin{array}{c}\text { Lama Penyangraian } \\
\text { (menit) }\end{array}$} & $\begin{array}{c}\text { Rerata } \\
\text { kadar } \\
\text { total }\end{array}$ \\
\cline { 2 - 5 } Suhu $\left({ }^{\circ} \mathbf{C}\right)$ & $\mathbf{5}$ & $\mathbf{1 0}$ & $\mathbf{1 5}$ & $\begin{array}{c}\text { asam } \\
\mathbf{( \% d b )}\end{array}$ \\
\hline $\mathbf{1 9 0}$ & $2,67(\mathrm{e})$ & $2,66(\mathrm{e})$ & $2,21(\mathrm{de})$ & $2,52(\mathrm{c})$ \\
$\mathbf{2 0 0}$ & $1,77(\mathrm{~cd})$ & $1,34(\mathrm{bc})$ & $1,15(\mathrm{~b})$ & $1,42(\mathrm{~b})$
\end{tabular}

\begin{tabular}{|c|c|c|c|}
\hline 210 & $0,88(\mathrm{ab})$ & $0,89(\mathrm{ab})$ & 0,44 (a) \\
\hline $\begin{array}{l}\text { Rerata kadar } \\
\text { total asam } \\
(\% d b)\end{array}$ & 1,78 (a) & 1,63 (b) & 1,27 (c) \\
\hline $\begin{array}{l}\text { Keterangan : } \\
\text {-Huruf yang } \\
\text { pada perlakus } \\
\text {-Huruf yang } \\
\text { pada perlakus }\end{array}$ & $\begin{array}{l}\text { oeda } n \\
\text { Berbe } \\
\text { na me } \\
\text { Tidak }\end{array}$ & $\begin{array}{l}\text { andakan } \\
\text { Nyata). } \\
\text { dakan } \mathrm{t} \\
\text { rbeda } \mathrm{N}\end{array}$ & $\begin{array}{l}\text { nya interaksi } \\
\text { adanya interaksi }\end{array}$ \\
\hline
\end{tabular}

Berdasarkan tabel di atas dapat diketahui bahwa persentase total asam tertitrasi akan semakin menurun seiring dengan menaiknya suhu dan lama penyangraian diduga karena semakin tinggi suhu dan lama penyangraian mengakibatkan senyawasenyawa asam menguap karena proses pemanasan. Hasil total asam tertinggi terdapat pada perlakuan suhu $190^{\circ} \mathrm{C}$ dengan lama penyangraian 5 menit dan yang terendah terdapat pada perlakuan suhu $210^{\circ} \mathrm{C}$ dengan lama penyangraian 15 menit. Sesuai dengan Mulato (2002) semakin tinggi suhu dan lama penyangraian akan mengakibatkan senyawa asam alifatik terdekomposisi menjadi gas $\mathrm{CO} 2$.

\section{Warna}

Intensitas warna kopi diukur menggunakan Chromameter Minolta CR-400. Alat ini menggunakan sistem CIE L, a, dan b. Nilai L, a, b, diubah dari sistem koordinat persegi menjadi sistem koordinat silinder. Nilai L menunjukkan kecerahan warna putih antara 0 sampai +100 , a menunjukkan warna kemerahan antara 0 sampai +60 dan warna kehijauan antara 0 sampai -60 , b menunjukkan warna kekuningan antara 0 sampai +60 dan warna kebiruan antara 0 sampai -60.

Berdasarkan hasil analisis sidik ragam menunjukkan bahwa variasi suhu dan lama penyangraian terhada kopi Arabika Gayo tidak memberikan pengaruh berbeda nyata pada taraf signifikansi $5 \%$ terhadap nilai $\Delta \mathrm{E}$ kopi yang dihasilkan. Hasil analisis intensitas warna kopi Arabika Gayo dapat dilihat pada tabel berikut. Tabel 17. Tabel Warna Kopi Arabika Gayo Aceh

\begin{tabular}{|c|c|c|c|c|}
\hline \multirow[t]{2}{*}{ Perlakuan } & \multicolumn{4}{|c|}{ Warna } \\
\hline & $\mathbf{L}$ & $\mathbf{a}$ & b & $\Delta \mathbf{E}$ \\
\hline $190^{\circ} \mathrm{C} 5^{\prime}$ & $31,65(\mathrm{e})$ & $8,82(\mathrm{~g})$ & $9,81(\mathrm{~g})$ & 34,29 (b) \\
\hline $190^{\circ} \mathrm{C} 15^{\prime}$ & $\begin{array}{l}31,36 \\
\text { (de) }\end{array}$ & 8,40 (f) & 9,29 (f) & 33,74 (b) \\
\hline $190^{\circ} \mathrm{C} 15^{\prime}$ & $31,10(d)$ & 8,27 (f) & $8,55(\mathrm{e})$ & $33,30(b)$ \\
\hline $200^{\circ} \mathrm{C} 5^{\prime}$ & $25,51(\mathrm{c})$ & $4,43(\mathrm{e})$ & $1,27(\mathrm{~d})$ & $\begin{array}{l}25,92 \\
(\mathrm{ab})\end{array}$ \\
\hline $200^{\circ} \mathrm{C} 10^{\prime}$ & 24,86 (b) & $3,66(d)$ & $0,36(\mathrm{c})$ & 25,13 (a) \\
\hline $200^{\circ} \mathrm{C} 15^{\prime}$ & $24,10(\mathrm{~b})$ & 2,493 (c) & $-0,81(b)$ & 24,25 (a) \\
\hline
\end{tabular}


$210^{\circ} \mathrm{C} 5, \quad 23,40$ (a) 1,7 (b) $\quad-1,46$ (a) 23,47 (a) $210^{\circ} \mathrm{C} 10^{\prime} 23,19$ (a) 1,58 (a) $-1,55$ (a) 23,29 (a) $210^{\circ} \mathrm{C} 15,23,15$ (a) 1,4 (a) $\quad-1,62$ (a) 23,26 (a) Keterangan : L* adalah Lightness antara $0-100$ adalah warna putih

a* adalah warna merah antara 0 - 60 dan warna hijau antara $0-(-60)$

$b^{*}$ adalah warna kuning antara $0-60$ dan warna biru antara $0-(-60)$

Berdasarkan tabel di atas dapat dilihat hasil analisis intensitas warna kopi dengan variasi suhu dan lama waktu penyangraian diperoleh nilai $\mathrm{L}^{*}$ memiliki kisaran 31,65-23,15 yang menunjukkan warna putih semakin kehitaman, nilai a* berkisar antara $8,82-1,4$ yang menunjukkan warna semakin hijau gelap, nilai $b^{*}$ berkisar antara 9,81-1,62 menunjukkan warna kuning semakin gelap dan nilai $\Delta \mathrm{E}$ berkisar antara 34,29-23,26 menunjukkan warna terang menjadi semakin gelap.

Pengujian intensitas warna dilakukan menggunakan alat colormeter hunter. Sistem notasi warna hunter dicirikan dengan 3 parameter warna yaitu warna kromatik (a*) menyatakan warna kromatik campuran merah hijau dengan nilai $+a^{*}$ dari 0 sampai +100 untuk warnamerah dan $-a^{*}$ dari 0 sampai -70 untuk warna hijau, intensitas warna $\left(b^{*}\right)$ menyatakan warna kromatik campuran biru-kuning dengan nilai $+b^{*}$ dari 0 sampai +70 untuk warna kuning dan $-\mathrm{b}^{*}$ dari 0 sampai -70 untuk warna biru dan tingkat kecerahan $\left(\mathrm{L}^{*}\right)$ (Andarwulan dkk, 2011). Sedangkan nilai $\Delta \mathrm{E}$ menyatakan kecerahan produk sesungguhnya (Hasanah, 2007).

Hasil penelitian ini menunjukkan bahwa suhu dan lama penyangraian mempengaruhi warna kopi Arabika Gayo. Semakin tinggi suhu dan lama waktu penyangraian maka warna kopi akan menjadi semakin gelap.

\section{Kesukaan Seduhan}

Uji organoleptik kesukaan seduhan dengan metode hedonik. Pengujian dengan metode hedonik ini bersifat sangat subjektif karena didasarkan atas penilaian pribadi masing-masing individu yang menjadi panelis. Hasil uji organoleptik terhadap kesukaan bertujuan untuk mengetahui respon panelis mengenai kesukaannya terhadap kopi yang dihasilkan pada masing-masing perlakuan suhu dan lama penyangraian.Hasil uji organoleptik rasa kopi yang dihasilkan dapat dilihat pada tabel berikut.

Tabel 18. Organoleptik kesukaan seduhan kopi Arabika Gayo

\begin{tabular}{lccl}
\hline \multicolumn{4}{c}{ Kesukaan Seduhan } \\
\hline Perlakuan & Rerata & Notasi & Keterangan \\
\hline $190^{\circ} \mathrm{C} ; 5^{\prime}$ & 2,86 & abc & $5=$ Sangat Suka \\
$190^{\circ} \mathrm{C} ; 10^{\prime}$ & 2,6 & $\mathrm{a}$ & $4=$ Suka \\
$190^{\circ} \mathrm{C} ; 15^{\prime}$ & 2,7 & $\mathrm{ab}$ & $3=$ Sedikit Suka \\
$200^{\circ} \mathrm{C} ; 5^{\prime}$ & 3,3 & $\mathrm{~cd}$ & $2=$ Tidak Suka \\
$200^{\circ} \mathrm{C} ; 10^{\prime}$ & 3,53 & $\mathrm{~d}$ & $1=$ Sangat Tidak \\
$200^{\circ} \mathrm{C} ; 15^{\prime}$ & 3,23 & $\mathrm{bcd}$ & Suka \\
$210^{\circ} \mathrm{C} ; 5^{\prime}$ & 2,73 & $\mathrm{ab}$ & \\
$210^{\circ} \mathrm{C} ; 10$, & 2,76 & $\mathrm{abc}$ & \\
$210^{\circ} \mathrm{C} ; 15^{\prime}$ & 2,63 & $\mathrm{a}$ & \\
\hline
\end{tabular}

Keterangan :

-Huruf yang berbeda menandakan adanya interaksi pada perlakuan (Berbeda Nyata).

-Huruf yang sama menandakan tidak adanya interaksi pada perlakuan (Tidak Berbeda Nyata).

Hasil analisis ragam menunjukkan bahwa perbedaan suhu dan lama waktu penyangraian berbeda nyata terhadap kesukaan seduhan kopi Arabika Gayo. Rerata tertinggi pengujian organoleptik kesukaan pada seduhan kopi Arabika Gayo terdapat pada perlakuan suhu $200^{\circ} \mathrm{C}$ dengan lama penyangraian 10 kesukaan yang paling disukai sedangkan rerata terendah terdapat pada perlakuan suhu $190^{\circ} \mathrm{C}$ dengan lama penyangraian 5 menit dan pada perlakuan suhu $210^{\circ} \mathrm{C}$ dengan lama penyangraian 15 menit yaitu 2,6 dan 2,63 yang berarti memiliki tingkat kesukaan yang paling tidak disukai.menit yaitu 3,53 yang berarti memiliki tingkat

Tabel di atas menunjukkan bahwa rerata kesukaan seduhan kopi Arabika Gayo dengan suhu dan lama penyangraian yang berbeda memiliki tingkatan kesukaan dari suka hingga tidak suka, menunjukkan skoring dari kisaran 3,53\%-2,6 (suka-tidak suka). Hal ini menunjukkan perlakuan suhu dan lama waktu penyangraian yang berbeda mempengaruhi tingkat kesukaan seduhan kopi yang diterima oleh panelis dengan menggunakan indra pengecap. Pada gambar 20 maka dapat diketahui bahwa seduhan yang paling disukai oleh panelis adalah seduhan kopi yang memilikiwarna, aroma dan rasa yang lebih seimbang seperti pada perlakuan suhu $200^{\circ} \mathrm{C}$ dengan lama penyangraian 10 menit. 


\section{KESIMPULAN}

Berdasarkan data hasil penelitian dapat diambil simpulan bahwa kenaikan suhu dan lama penyangraian mempengaruhi karakteristik (fisik dan kimia), dan kesukaan konsumen kopi Arabika Gayo yang meliputi, variasi suhu dan lama waktu penyangraian berpengaruh nyata terhadap warna, rendemen, kadar air, total asam dan kesukaan pada kopi tetapi tidak berpengaruh nyata terhadap kadar abu, kadar lemak dan kadar kafein.

Semakin tinggi suhu dan lama waktu terhadap penyangraian maka akan menurunkan rendemen, kadar air dan total asam pada kopi.

Hasil terpilih didapatkan pada perlakuan suhu $200^{\circ} \mathrm{C}$ dengan lama penyangraian 10 menit yang memiliki rendemen sebesar 78,5\%, kadar air $1,34 \%$, kadar abu 4,55(\%db), kadar lemak $14,48(\% \mathrm{db})$, kafein $0,87(\% \mathrm{db})$, total asam $1,34(\% \mathrm{db})$ dan skor organoleptik 3,53 yang berarti suka dan sedikit suka.

\section{DAFTAR PUSTAKA}

Andarwulan, N, Kusnandar, F, Herawati, D. (2011). Analisis Pangan. Dian Rakyat. Jakarta.

Buffo, R, A , and Cardelli-Freire, C. (2004) Coffee Flavour: An Overview, Flavour and Fragrance Journal. 19, 00. 99-104.

Estiasih,T dan Ahmadi, K. (2009).Teknologi Pengolahan Pangan. Bumi Aksara, Malang.

Harris, R. S. dan E. Karmas. (1989). Evaluasi Gizi pada Pengolahan Bahan Pangan. Penerjemah: S. Achmadi. ITB - Press, Bandung.

Hasanah, I. (2007). Bercocok Tanam Padi. Azka Mulia Media. Jakarta. 68 hal.

Heinrich, Michael., Barnes, J., Gibbson, S., Williamsom, M.E. (2010). Farmakognosi Dan Fitoterapi, Jakarta, Buku Kedokteran EGC.

Herawati, D. A. dan Wibawa. D. A. 2009. Pengaruh Konsentrasi Susu Skim dan Waktu Fermentasi Terhadap Hasil Pembuatan Soyghurt. Jurnal Ilmiah Teknik Lingkungan. Vol. 1 (2): 48-58.

Kuntjahjawati dan Darmadji, P. (2004). Identifikasi komponen volatil asap cair daun tembakau (Nicotiana Tabacum L.) rajangan. Fakultas Teknologi Pertanian. UGM.
Yogyakarta. Agritech. 24(1): 17-22.

Mangiwa, S. (2013). Penyiapan kandidat reference material untuk penentuan kafein dan asam klorogenat dalam biji kopi hijau secara kromatografi lapis tipis kinerja tinggi (HPTLC). Tesis. Bandung : ITB.

Mulato, S. (2002). Pemanfaatan Alat Dan Mesin Pengolahan Produk Primer Dan Sekunder Kopi Skala Kelompok. Pusat Penelitian Kopi Dan Kakao, Jember.

Sivetz, M. (1979). Coffee Technology. The AVI Publishing Company, Inc., Westport, Connecticut.

Yuhandini, I dan Rejo. (2008). Analisis Mutu Kopi Sangrai Berdasarkan Tingkat Mutu Biji Kopi Beras. Program Studi Teknik Pertanian UNSRI. Indralaya. 